University at Albany, State University of New York

Scholars Archive

Psychology Faculty Scholarship

Psychology

2009

\title{
Correlates of Serious Suicidal Ideation and Attempts in Female Adult Sexual Assault Survivors
}

Sarah E. Ullman

The University of Illinois at Chicago

Cynthia J. Najdowski

University at Albany, State University of New York, cnajdowski@albany.edu

The University at Albany community has made this article openly available.

Please share how this access benefits you.

Follow this and additional works at: https://scholarsarchive.library.albany.edu/psychology_fac_scholar

Part of the Clinical Psychology Commons, Counseling Commons, Counseling Psychology Commons, Criminology and Criminal Justice Commons, Domestic and Intimate Partner Violence Commons, Gender and Sexuality Commons, and the Social Psychology Commons

\section{Recommended Citation}

Ullman, Sarah E. and Najdowski, Cynthia J., "Correlates of Serious Suicidal Ideation and Attempts in Female Adult Sexual Assault Survivors" (2009). Psychology Faculty Scholarship. 27.

https://scholarsarchive.library.albany.edu/psychology_fac_scholar/27

This Article is brought to you for free and open access by the Psychology at Scholars Archive. It has been accepted for inclusion in Psychology Faculty Scholarship by an authorized administrator of Scholars Archive.

Please see Terms of Use. For more information, please contact scholarsarchive@albany.edu. 
Running head: CORRELATES OF SERIOUS SUICIDAL IDEATION AND ATTEMPTS

PRE-PRINT. This paper is not the copy of record and may not exactly replicate the authoritative document published in the journal.

Correlates of Serious Suicidal Ideation and Attempts in Female Adult Sexual Assault Survivors

Sarah E. Ullman, Ph.D.

Cynthia J. Najdowski, B.A.

University of Illinois at Chicago

Acknowledgements: This research was supported by a grant from NIAAA \#13455 to Sarah Ullman. An earlier version of this paper was presented at the 2008 American Association of Suicidology meeting in Boston, MA

Contact Information: 
Sarah E. Ullman, Ph.D.

Criminal Justice Department

University of Illinois at Chicago

1007 West Harrison Street

Chicago, IL 60607-7140

Email: seullman@uic.edu

Tel: 312-996-6679 


\begin{abstract}
Relations between (a) serious suicidal ideation and attempts and (b) demographics, trauma history, assault characteristics, post-assault outcomes, and psychosocial variables were examined among female adult sexual assault survivors. Younger, minority, and bisexual survivors reported greater ideation. More traumas, drug use, and assault disclosure related to greater attempts, whereas perceived control over recovery was related to fewer attempts. Child sexual abuse and some assault characteristics predicted suicidal behavior. Depression was related to suicidal behavior until psychosocial variables were accounted for. Specifically, using substances to cope and self-blame predicted greater ideation, whereas receiving aid/information support was related to less ideation. Implications for research and treatment are discussed.
\end{abstract}


Correlates of Serious Suicidal Ideation and Attempts in Female Adult Sexual Assault Survivors

Research shows that adult sexual assault (ASA) is associated with increased risk of suicidal behavior in women, including suicidal ideation and attempts (see Ullman, 2004 for a review). Yet, studies of survivor samples differentiating those engaging in suicidal behavior from those who do not are uncommon. Given their higher risk for suicidal behavior, this subgroup of women warrants increased attention, especially in community samples, which have been studied less often than those already identified by treatment providers. Therefore, we examined the relations between (a) serious suicidal ideation and attempts and (b) demographics, trauma history, assault characteristics, post-assault outcomes, and psychosocial variables in a large, diverse sample of women survivors recruited from the community.

In an analysis of data from the National Comorbidity Survey (NCS), Ullman and Brecklin (2002) examined the effects of child sexual abuse (CSA) and assault-related and psychosocial factors associated with risk of suicidal ideation and attempts in a subsample of women ASA survivors. Demographic risk factors were examined because past research suggests that younger, less educated, unemployed, and ethnic minority persons (e.g., Hispanics, African Americans) may be at higher risk for non-fatal suicidal behavior (Canetto \& Lester, 1995). As predicted, Ullman and Brecklin found that younger age was associated with suicidal ideation. Several other important findings from this study will be reviewed subsequently, but the NCS data used by Ullman and Brecklin did not assess many variables that may be important correlates of suicidal behavior in these women. For example, research also suggests that sexual orientation is associated with psychological distress and substance use/abuse in women who have experienced ASA (Hughes, Johnson, \& Wilsnack, 2001). These and other correlates of minority sexual orientation (e.g., increased risk of more severe sexual assaults; Long, Ullman, Long, 
Mason, \& Starzynski, 2007) may confer a greater risk for suicidality for lesbian or bisexual compared to heterosexual survivors. Thus, we predicted that demographics (i.e., age, employment, sexual orientation, ethnicity) would relate to suicidality.

CSA in particular is also associated with suicidal behavior in women and may be more strongly related than later (adolescent/adult) sexual victimization (Stepakoff, 1998). For example, Ullman and Brecklin (2002) found that women with histories of both CSA and ASA were significantly more likely to attempt suicide than were women who experienced ASA only, controlling for demographic factors and other psychosocial characteristics. Although the association of CSA and ASA with suicidal behavior is commonly observed in studies, CSA is rarely disclosed in childhood, and even ASA, is often not acknowledged or disclosed to others until months or years later (see Ullman, 1999; Ullman, 2003 for reviews). Thus, research is needed to understand the impact of various life history factors that may influence risk of suicidal behavior in ASA survivors. For example, consistent with past research suggesting that stressful and traumatic life events affect suicide outcomes (Chaudron \& Caine, 2004), Ullman and Brecklin found that, in ASA survivors, stressful life events were associated with suicidal ideation and that more traumatic life events predicted increased likelihood of suicide attempts. Further study is needed, however, particularly in the context of other childhood and adulthood life stressors, to more clearly elucidate both the role of survivors' trauma histories and other risk and protective factors in predicting suicidal behavior. We predicted that trauma histories of CSA and other traumatic life events would relate to suicidality.

Assault characteristics of completed rape and physical force have been shown to relate to suicidal ideation and attempts in college women (Stepakoff, 1998), but research has not replicated these relations in community samples. Thus, assault characteristics such as completed 
rape and multiple offenders were examined as more violent assaults may relate to suicidality (Stepakoff, 1998).

Post-assault outcomes, such as mental health, may also be important predictors of suicidal behavior in ASA survivors. For example, Molnar, Berkman, and Buka (2001) also analyzed the NCS data and found that women with a history of CSA were more likely to attempt suicide than those without. However, only $19 \%$ of serious attempts were attributed to CSA whereas $79 \%$ were attributed to psychiatric disorders, leading Molnar et al. (2001) to conclude that the strong association between CSA and suicidal behavior may be partially mediated by psychopathology. In addition, among NCS study participants who had experienced ASA, Ullman and Brecklin (2002) found that depression and post-traumatic stress disorder (PTSD) were associated with suicidal ideation, and more depression predicted increased lifetime odds of suicide attempts.

Because substance use problems may be related to suicidal ideation and behavior (Gomberg, 1989; Grant \& Hasin, 1999), it is also important for researchers to consider this risk factor in samples of ASA survivors. Ullman and Brecklin found that alcohol dependence symptoms were associated with suicidal ideation, but no research to date has examined the role of illicit drug use in predicting suicidal behavior in ASA survivors. Thus, in our study, psychological symptoms of PTSD, depression, alcohol problem symptoms, and past-year illicit drug use were examined as evidence suggests all of these factors may confer risk of suicidality in victimized women who often have higher rates of these problems (Ullman, 2004).

The unique effects of post-assault drinking and drug use on suicidal behavior should be examined, but it is also important to explore these and other specific strategies that women engage in to cope with ASA. For example, self-medication with alcohol/drugs and avoidance 
coping are associated with greater PTSD, depression, and alcohol problems in CSA and ASA victims (Frazier, 2000; Runtz \& Schallow, 1997; Ullman, Filipas, Townsend, \& Starzynski, 2005; Valentiner, Riggs, Foa, \& Gershuny, 1996), all of which are also associated with suicidal behavior (Ullman, 2004). Although research has shown that life meaning was a buffer between an emotion-focused coping style and suicidal ideation in college women (Edwards \& Holden, 2001), the role that other coping strategies may play in mediating the effects of ASA on suicidal behavior has yet to be examined. Social support also appears to be important and has been studied as a general protective factor (Chaudron \& Caine, 2004; Ullman \& Brecklin, 2002), but specific social interactions or reactions to ASA disclosures (Kaslow et al., 2002) have not been examined as risk factors for suicidality, despite findings that specific social reactions to ASA disclosures are often related to PTSD (Ullman \& Filipas, 2001a; Ullman, Townsend, Filipas, \& Starzynski, 2007). Other potentially protective factors, such as perceived control over recovery (which has been found to relate to fewer PTSD symptoms in ASA survivors; Frazier, 2003), also have not been examined in relation to suicidal behavior. Thus, we examined perceived control over recovery (Frazier, 2003) and general social support measures which may be protective against suicidality (e.g., getting along with others, satisfaction with social support), as well as ASA disclosure to support sources, coping strategies, and social reactions to disclosures, which were also expected to relate to suicidality.

\section{Method}

\section{Participants and Procedure}

A large, diverse sample of ASA survivors was recruited via advertisements in local newspapers and fliers distributed throughout the Chicago metropolitan area on college campuses, around the community (e.g., bookstores), to mental health agencies, and rape crisis centers. 
Women aged 18 or older with unwanted sexual experiences since age 14 were invited to participate in a confidential mail survey. Interested women were mailed the survey along with a cover letter and information sheet describing the study, and a list of community resources for women survivors of violence. Women received $\$ 20$ for completing the survey and were offered a summary of the results. Of women requesting the initial survey, 1,084 returned it, a 90\% response rate. Our sample includes 969 women who reported having experienced ASA. All participants were treated according to ethical guidelines of the University of Illinois at Chicago. Measures

Demographics. Participants reported their age at the time of the survey $(M=32, S D=$ 11), current employment status (yes/no; 49\% were employed), sexual orientation (dummy coded with heterosexuals as the reference group; $77 \%$ were heterosexual, $6 \%$ lesbian, and $12 \%$ bisexual), and ethnicity (Caucasian/minority; 40\% were Caucasian).

Trauma history. CSA history was measured using a modified version of the Sexual Experiences Survey (SES; Koss \& Gidycz, 1985). Following Koss, Gidycz, and Wisniewski (1987), women were asked whether they had experienced completed rape, attempted rape, sexual coercion, or unwanted sexual contact before age 14 years. This variable was dichotomized (yes/no; $44 \%$ of women in our sample reported experiencing CSA). Traumatic life events were assessed with Goodman, Corcoran, Turner, Yuan, and Green's (1998) Stressful Life Events Screening Questionnaire, a brief self-report measure of ten behaviorally-specific items assessing a variety of traumatic events of an interpersonal nature. This measure was scored as the summed number of events experienced by each respondent (excluding ASA and CSA which were assessed by the SES; $M=3.17, S D=2.12$ ).

Assault characteristics. A modified version of the SES (Koss \& Gidycz, 1985) was used 
to identify women who had experienced completed rape, attempted rape, sexual coercion, and unwanted sexual contact at age 14 years or older. ASA was assessed dichotomously (yes/no: all women in this sample experienced ASA). Women also reported whether they experienced completed rape $(77 \%)$ and whether there were multiple perpetrators $(17 \%)$. Women reporting multiple ASAs were asked questions about their most serious assault.

Post-assault outcomes. The Posttraumatic Stress Diagnostic Scale (PDS; Foa, 1995) is a standardized 17-item self-report instrument used to provide a PTSD diagnosis (yes/no) using DSM-IV criteria. Women rated how often each symptom (i.e., re-experiencing/intrusion, avoidance/numbing, hyperarousal) had bothered them in relation to the assault during the past 30 days on a 4-point scale ranging from 0 (not at all) to 3 (almost always). The PDS has acceptable test-retest reliability $(\kappa=.74)$ for a PTSD diagnosis in ASA survivors over a two-week interval (Foa, Cashman, Jaycox, \& Perry, 1997). In our sample, 67\% of women met criteria for PTSD. Depression was assessed with the CESD-10 (Andresen, Carter, Malmgren, \& Patrick, 1994), a shortened version of the Center for Epidemiologic Studies-Depression Scale, a screening scale developed to measure current depressive symptomatology in the general population (Radloff, 1977). Ten items were rated on a 4-point scale (range $=0$ to 3 ) according to how often the respondent felt that way during the past week. The total score is the sum of the items after reversing the two positive mood items with higher scores indicating a higher level of depressive symptoms. Following Andresen et al. (1994), we used 10 or more points to indicate a significant level of depressive symptoms (yes/no), which $64 \%$ of women in our sample experienced. Cronbach's alpha of the CES-D was found to be .85 in the general population and .90 for patients and the content, concurrent, and discriminant validity have been supported (Radloff, 1977; Weissman, Sholomskas, Pottenger, Prusoff, \& Locke, 1977). The CESD-10 
correlates highly with the 20-item scale (Pearson's $r=.97$; Andresen et al., 1994).

The Michigan Alcoholism Screening Test (MAST; Selzer, 1971) was used to assess pastyear problem drinking (yes/no). The MAST is a widely used, 25-item standardized self-report screening instrument for alcohol abuse and dependence. The MAST has good internalconsistency reliability $(\alpha=.91)$ with a psychiatric outpatient sample (Zung, 1980). Based on Selzer's (1971) guidelines, 30\% of women in our sample were categorized as problem drinkers. Illicit drug use was measured by asking participants if they had used any of the following substances in the past year: marijuana/hashish, psychedelics (e.g., LSD, Ecstasy), cocaine, and/or heroin (yes/no), which was the case for $47 \%$ of women.

Psychosocial variables. Participants were asked about their current social support network using the Social Activities Questionnaire of the Rand Health Insurance Experiment (Donald \& Ware, 1984). One item from this measure assessed how well women rated they were getting along with others on a 3-point scale ranging from 1 (better than usual) to 3 (not as well as usual; $M=1.92, S D=.67)$. We also asked women if they had disclosed their ASA to a formal source (e.g., medical doctor, psychologist; yes/no), and $47 \%$ of women reported that they had. On a 4-point scale ranging from 1 (very unsatisfied) to 4 (very satisfied), women rated their overall satisfaction with support received from everyone to whom they disclosed their ASA $(M=$ 2.79, $S D=1.01$ ). The Social Reactions Questionnaire (SRQ; Ullman, 2000) was administered to survivors who had disclosed their assaults to others. They were asked to report how often they received 48 different social reactions received since the assault on a scale ranging from 0 (never) to 4 (always). Subscales were calculated for the following categories of responses: providing emotional support $(M=2.29, S D=.87)$, taking control of the victim's decisions $(M=.97, S D=$ $.75)$, distraction/discouraging talking $(M=1.26, S D=.84)$, treating the victim differently/stigma 
$(M=.87, S D=.84)$, providing aid/information $(M=1.14, S D=.98)$, and blaming the victim $(M$ $=.77, S D=.92$ ). The SRQ has good test-retest reliability (Pearson $r$ ranged from .68 to .77;

Ullman, 2000).

Perceived control over recovery from the ASA during the past 30 days was assessed on a scale ranging from 1 (strongly disagree) to 5 (strongly agree; $M=3.71, S D=.71$ ), using five items developed by Frazier (2003) to assess present control. Frazier reported an alpha of .81 for present control over recovery from assault. Various coping strategies used in the past 30 days to cope with the assault were assessed using the Brief COPE (Carver, Scheier, \& Weintraub, 1989), a 28-item self-report scale, with Likert items ranging from 1 (I didn't do this at all) to 4 (I did this a lot). Several coping strategies were measured by computing the unweighted sum of responses to items composing the substance use $(M=3.82, S D=2.28)$, behavioral disengagement $(M=3.45, S D=1.68)$, humor $(M=2.82, S D=1.53)$, acceptance $(M=5.82, S D=$ $1.85)$, and self-blaming $(M=4.51, S D=2.04)$ subscales. The COPE, widely used in studies of stressed populations, has adequate internal consistency reliability (all subscales alphas .60 or greater except for one) and test-retest reliability (correlations of .46 to .86; Carver et al., 1989). In our sample, subscale alphas ranged from .60 to .93 .

Dependent variables. Serious suicidal ideation was assessed by asking participants if they had ever seriously thought about killing themselves. Suicide attempts were assessed by asking participants if they had ever tried to kill themselves. Serious suicidal ideation was reported by $53 \%$ of women, and $28 \%$ reported attempts.

Results

Analyses were conducted in two steps to determine which factors related to serious suicidal ideation and attempts. First, bivariate analyses were conducted to determine whether 
there were significant differences between women who thought about or attempted suicide and those who did not. Chi-square analyses were run on dichotomous independent variables and point-biserial correlations were run on continuous independent variables. ${ }^{1}$ Variables significant at $p \leq .005$ were entered into hierarchical logistic regression models predicting whether women reported any serious suicidal ideation or attempts in five blocks. Given our large, heterogeneous sample, demographics were entered in Block 1 to account for any differences in serious suicidal ideation and attempts due to age, employment status, sexual orientation, or ethnicity. Block 2 included the trauma history variables of CSA history and traumatic life events. Block 3 included the assault characteristics of completed rape or multiple perpetrators. Block 4 included the trauma-related outcomes of PTSD, depression, problem drinking, and illicit drug use. Block 5 included psychosocial variables related to experiences of social support, control, coping, and social reactions to ASA disclosure. Only respondents without missing data were included in bivariate analyses: Ns ranged from 724 to 960 . Missing data randomly distributed across variables in the regression models further reduced the sample, although by using pairwise deletion in the regression we preserved 544 and 440 valid cases in the models predicting serious suicidal ideation and attempts, respectively.

\section{Serious Suicidal Ideation}

The hierarchical logistic regression model predicting serious suicidal ideation included 20 variables and was statistically significant, $\chi^{2}(20,544)=74.20, p<.001$, explaining approximately $17 \%$ of the variance in serious suicidal ideation. Table 1 presents regression coefficients (B), Wald, and odd ratio $(O R)$ statistics for each variable in each entry set. ${ }^{2}$ As predicted, demographic variables entered in Block 1 were associated with serious suicidal ideation. Older women and Caucasians were significantly less likely to think about suicide than 
were younger or minority women. Compared to heterosexuals, bisexuals were marginally more likely to think about suicide. A history of CSA was marginally associated with serious suicidal ideation, but other traumatic life events were not. Having multiple offenders was also marginally related to serious suicidal ideation. Women who had a significant level of depression symptoms were marginally more likely to think about suicide than other women, but PTSD diagnosis and illicit drug use were not related to serious suicidal ideation. Finally, psychosocial variables were entered in the fifth block of the model. Using substances to cope with distress and self-blame were significantly related to increased serious suicidal ideation. Receiving aid and information support from sources of disclosure, however, was a protective factor and predicted a significantly lower likelihood of serious suicidal ideation in women who experienced ASA. Getting along well with others, satisfaction with social support, behavioral disengagement, acceptance, emotional support, controlling reactions, and being treated differently from sources of disclosure were not related to serious suicidal ideation.

\section{Suicide Attempts}

The hierarchical logistic regression model predicting suicide attempts included 23 variables and was statistically significant, $\chi^{2}(23,440)=79.99, p<.001$, explaining approximately $23 \%$ of the variance in suicide attempts. See Table 1 for regression coefficients (B), Wald, and odd ratio $(O R)$ statistics for each variable in each entry set. Neither employment status nor sexual orientation was significantly related to suicide attempts. A history of CSA was significantly and positively related to suicide attempts, and traumatic life events were marginally associated with suicide attempts. Women who experienced completed rape were marginally more likely to attempt suicide than women who did not. Having multiple offenders, however, did not significantly predict suicide attempts. Post-assault outcomes of PTSD, depression, and 
problem drinking were not related to suicide attempts, but illicit drug use was a marginal predictor of suicide attempts. Finally, psychosocial variables were entered in the fifth block of the model. Women who disclosed their assault to formal sources were significantly more likely to attempt suicide, but women who perceived greater control over their recovery were marginally less likely to attempt suicide. Getting along well with others, satisfaction with social support, and the subscales from the COPE and SRQ were not significantly related to suicide attempts.

\section{Discussion}

This study examined correlates of serious suicidal ideation and attempts in a diverse urban community sample of women ASA survivors. We used conservative analyses to assess multiple variable domains (i.e., demographics, trauma history, assault characteristics, postassault psychological and substance use outcomes, and psychosocial factors) that may be relevant to understanding these suicidal behaviors in ASA survivors. In final hierarchical logistic regression models with all variables entered, both age and ethnicity were significantly related to greater serious suicidal ideation with younger and minority women at greater risk than older and Caucasian women, consistent with previous research (Ullman \& Brecklin, 2002). Being bisexual was marginally associated with greater risk of serious suicidal ideation, which had not been examined in prior studies and needs to be replicated, although a sample of college students in Turkey found that CSA and identifying as bisexual or homosexual were each related to suicidal ideation (Eskin, Kaynak-Demir, \& Demir, 2005) and in the National Violence Against Women Survey women who had sex with women had higher risk of suicidal ideation than women who had sex with men (Lhomond \& Saurel-Cubizolles, 2006). Greater mental health symptoms, such as PTSD, in bisexual women who have experienced sexual assault may explain this finding (Long et al., 2007). 
Both having a history of CSA and experiencing ASA by multiple assailants were associated with greater serious suicidal ideation, whereas more traumatic life events were marginally associated with an increased risk of suicide attempts. This is consistent with some past research (Ullman \& Brecklin, 2002). The finding regarding multiple assailant assaults is new and important given that gang rapes seem to pose more serious risks to the mental and physical health of survivors than single offender rapes (Ullman, 2007). Depression, coping by using substances, and coping by blaming one's self were associated with greater serious suicidal ideation. Prior research shows depression to be highly related to suicidality in victims (Kaslow, Thompson, Brooks, \& Twomey, 2000; Ullman \& Brecklin, 2002), and it appears that certain strategies for coping with ASA also may confer increased risk. Receiving more tangible aid/information support reactions from others told about assault was associated with less serious suicidal ideation. These types of reactions may be protective because positive forms of social support are associated with better rape recovery generally (Ullman, 1999).

Fewer factors were significant when all variables were entered into the model predicting suicide attempts. Demographics were not significant in the final model, but bisexuality and unemployment were related to suicide attempts until after post-assault symptoms and psychosocial factors were entered. This suggests that these symptoms and psychosocial factors may explain part of the risks for suicide attempts found in the full models including these variables. Consistent with past research (Ullman \& Brecklin, 2002), completed rape was associated with more reports of suicide attempts and CSA and traumatic life events were related to greater odds of suicide attempts, important information that reinforces the need to consider the role of cumulative trauma exposure (sexual and nonsexual) in affecting suicidality. This suggests that more severely traumatized women are at greater risk of suicidality and should be targeted for 
intervention.

Past year drug use and disclosure to formal support sources were each associated with greater likelihood of attempting suicide. Despite severely victimized women's greater contact with formal services, this relation likely reflects their greater suicidal behavior and not the potential helpfulness of those sources. Longitudinal research is needed to explore this relation, however, as ASA survivors report more negative experiences with formal than informal support sources (Golding, Siegel, Sorenson, Burnam, \& Stein, 1989; Ullman \& Filipas, 2001b). Control over assault recovery was marginally associated with less suicide attempts. Past research shows control over recovery to be related to less PTSD in ASA victims (Frazier, 2003), so future research should examine potential mediators of the relation between control over recovery and reduced likelihood of suicide attempts. Poorer mental health and other psychosocial risk factors, such as maladaptive coping and other social reactions to ASA disclosure, which were significantly related to suicidality at the bivariate, but not multivariate, level may be modifiable through treatment and intervention with survivors at higher risk for suicidality. These risk factors need further study in other representative samples of ASA survivors. Finally, it was somewhat surprising that depression was not related to suicide attempts in the final model as in past studies (Ullman \& Brecklin, 2002), but this may have been because other psychosocial factors included in our models had not been included in prior research. Alternatively, our measure of depression may not have been discriminating enough, as it was only a brief screening measure of depressive symptoms and not a diagnostic measure of depression.

These analyses are limited in being retrospective findings from a volunteer sample with lifetime measures of the dependent variables; thus we cannot discern direction of causality as suicidal behavior may have occurred prior to some independent variables. Despite this, our 
results suggest that various sets of risk factors may affect suicidality in women ASA survivors and need to be examined in longitudinal studies following survivors after their assaults. Demographic factors such as sexual orientation and ethnic minority status are important to look at in future research as well as exposure to other stressful and traumatic life events including CSA. Depression and substance use are also important factors that may contribute to greater suicidality in sexually victimized women. Finally, post-assault coping and social support network variables including social reactions to assault disclosure may be important factors for understanding differences in risk of suicidality in assaulted women. Perceived control over recovery from ASA, while significant in bivariate analyses, was only marginally related to fewer suicide attempts in the final model. This variable was found to protect against PTSD in other analyses of our data (Ullman et al., 2007) and in Frazier's (2003) longitudinal study, although PTSD did not contribute to suicidality in this analysis. It is possible that this variable is not protective against all negative outcomes, or that other factors like depression and trauma exposure are stronger correlates of suicidality. Although social support variables and positive coping strategies did not show protective effects as in some past research (Kaslow et al., 2000), tangible aid/information support reactions to ASA disclosures were associated with less suicidality. It is unclear why adaptive coping strategies were not significant in multivariate analyses, but future studies are needed to examine both coping and social support more fully in the future. It was arguably more difficult for these psychosocial factors to be significant in the final models because they were added in a fifth final block of predictors after all other variables had already been entered into the models. Thus, these variables captured variance not already explained by demographics, trauma history, assault characteristics, and post-assault outcomes already entered in the model. The observation that some psychosocial variables were 
significantly related to suicidality despite this conservative approach speaks to the robustness of their effects.

We have presented a general conceptual scheme which takes the risk factors of background variables (e.g., demographics, trauma history), assault variables, and post-assault responses and experiences into account to understand suicidal behavior in women who have experienced ASA, but future research would benefit from conceptualizing the interrelations of these risk factors in predicting serious suicidal ideation and attempts. For example, structural equation modeling could be used to determine whether coping strategies, self-blame, social support, and mental health outcomes (e.g., PTSD, problem drinking, substance use) mediate the effects of trauma histories and assault characteristics on suicidal behavior. Further research is needed to understand differences among women in the community with sexual assault histories in terms of their risk of possible suicidal behavior. Overall, there were few women who had attempted suicide in this sample, which may have made it harder to detect differences in the regression model as compared with the serious suicidal ideation model. It is unclear whether many of the psychosocial factors studied here may influence suicidality or be influenced by it without longitudinal analyses. Therefore, longitudinal research assessing the timing of assault, other traumatic and stressful events in relation to suicidal ideation and attempts is needed that includes psychosocial factors (e.g., post-assault coping, support seeking, substance use, and psychological symptoms of PTSD and depression) that may reduce or increase the risks sexual victimization experiences pose for women's mental health and suicidal behavior. 


\section{References}

Andresen, E. M., Carter, W. B., Malmgren, J. A., \& Patrick, D. L. (1994). Screening for depression in well older adults: Evaluation of a short form of the CES-D. American Journal of Preventive Medicine, 10, 77-83.

Canetto, S.S., \& Lester, D. (1995). Women and suicidal behavior. New York: Springer.

Carver, C.S., Scheier, M.F., \& Weintraub, J.K. (1989). Assessing coping strategies: A theoretically based approach. Journal of Personality and Social Psychology, 56, 267-283.

Chaudron, L.H., \& Caine, E.D. (2004). Suicide among women: A critical review. Journal of the American Medical Women's Association, 59, 125-134.

Donald, C.A., \& Ware, J.E. (1984). The measurement of social support. Research in Community and Mental Health, 4, 325-370.

Edwards, M.J., \& Holden, R.R. (2001). Coping, meaning in life, and suicidal manifestations: Examining gender differences. Journal of Clinical Psychology, 57, 1517-1534.

Eskin, M., Kaynak-Demir, H., \& Demir, S. (2005). Same-sex sexual orientation, childhood sexual abuse, and suicidal behavior in university students in Turkey. Archives of Sexual Behavior, 34, 185-195

Foa, E.B. (1995). Posttraumatic Stress Diagnostic Scale Manual. Minneapolis, MN: National Computer Systems, Inc.

Foa, E.B., Cashman, L., Jaycox, L., \& Perry, K. (1997). The validation of a self-report measure of PTSD: The Posttraumatic Stress Diagnostic Scale. Psychological Assessment, 9, 445451.

Frazier, P.A. (2000). The role of attributions and perceived control in recovery from rape. Journal of Personal and Interpersonal Loss, 5, 203-226.

Frazier, P.A. (2003). Perceived control and distress following sexual assault: A longitudinal test 
of a new model. Journal of Personality and Social Psychology, 84, 1257-1269.

Giaconia, R.M., Reinherz, H.Z., Silverman, A.B., Pakiz, B., Frost, A.K., \& Cohen, E. (1995). Traumas and posttraumatic stress disorder in a community population of older adolescents. Journal of the Academy of Child and Adolescent Psychiatry, 34, 1369-1380.

Golding, J.M., Siegel, J.M., Sorenson, S.B., Burnam, M.A., \& Stein, J.A. (1989). Social support sources following sexual assault. Journal of Community Psychology, 17, 92-107.

Gomberg, E.S.L. (1989). Suicide risk among women with alcohol problems. American Journal of Public Health, 79, 1363-1365.

Goodman, L.A., Corcoran, C., Turner, K., Yuan, N., \& Green, B.L. (1998). Assessing traumatic event exposure: General issues and preliminary findings for the Stressful Life Events Screening Questionnaire. Journal of Traumatic Stress, 11, 521-542.

Grant, B.F., \& Hasin, D.S. (1999). Suicidal ideation among the U.S. drinking population: Results From the National Longitudinal Alcohol Epidemiologic Survey. Journal of Studies on Alcohol, 60,_422-429.

Hughes, T.L., Johnson, T.P., \& Wilsnack, S.C. (2001). Sexual assault and alcohol abuse: A comparison of lesbians and heterosexual women. Journal of Alcohol Abuse, 13, 515-532.

Kaslow, N.J., Thompson, M.P., Brooks, A.E., \& Twomey, H.B. (2000). Ratings of family functioning of suicidal and nonsuicidal African American women. Journal of Family Psychology, 14, 585-599.

Kaslow, N.J., Thompson, M.P., Okun, A., Price, A., Young, S., Bender, M., Wyckoff, S., Twomey, H., Goldin, J., \& Parker, R. (2002). Risk and protective factors for suicidal behavior in abused African American women. Journal of Consulting and Clinical Psychology, 20, 311-319.

Koss, M.P., \& Gidycz, C.A. (1985). The sexual experiences survey: Reliability and validity. 
Journal of Consulting and Clinical Psychology, 53, 442-443.

Koss, M.P., Gidycz, C.A., \& Wisniewski, N. (1987). The scope of rape: Incidence and prevalence of sexual aggression and victimization in a national sample of higher education students. Journal of Consulting and Clinical Psychology, 55, 162-170.

Lhomond, B., \& Saurel-Cubizolles, M. (2006). Violence against women and suicide risk: The neglected impact of same-sex sexual behaviour. Social Science \& Medicine. 62, 20022013.

Long, S., Ullman, S.E., Long, L., Mason, G., \& Starzynski, L. (2007). Women’s experiences of male-perpetrated sexual assault by sexual orientation. Violence and Victims, 22, 684-701.

McFarlane, J., Malecha, A., Gist, J., Watson, K., Batten, E., Hall, I., \& Smith, S. (2005). Intimate partner sexual assault against women and associated victim substance use, suicidality, and risk factors for femicide. Issues in Mental Health Nursing, 26, 953-967.

Molnar, B.E., Berkman, L.F., \& Buka, S.L. (2001). Psychopathology, child sexual abuse and Other childhood adversities: relative links to subsequent suicidal behavior in the US. Psychological Medicine, 31, 965-977.

Radloff, L.S. (1977). The CES-D Scale: A self-report depression scale for research in the general population. Applied Psychological Measurement, 1, 385-401.

Runtz, M.G., \& Schallow, J.R. (1997). Social support and coping strategies as mediators of adult adjustment following childhood maltreatment. Child Abuse and Neglect, 21, 211-226.

Selzer, M. (1971). The Michigan Alcoholism Screening Test: The quest for a new diagnostic instrument. American Journal of Psychiatry, 127, 1653-1658.

Stepakoff, S. (1998). Effects of sexual victimization on suicidal ideation and behavior in U.S. college women. Suicide and Life-Threatening Behavior, 28, 107-126.

Ullman, S.E. (1999). Social support and recovery from sexual assault: A review. Aggression and 
Violent Behavior: A Review Journal, 4, 343-358.

Ullman, S.E. (2000). Psychometric characteristics of the Social Reactions Questionnaire: A measure of reactions to sexual assault victims. Psychology of Women Quarterly, 24, 169183.

Ullman, S.E. (2003). Social reactions to child sexual abuse disclosures: A critical review. Journal of Child Sexual Abuse, 12, 89-121.

Ullman, S.E., (2004). Sexual assault victimization and suicidal behavior in women: A review of the literature. Aggression and Violent Behavior, 9, 331-351.

Ullman, S.E. (2007). Comparing gang and individual rapes in a community sample of urban women. Violence and Victims, 22, 43-51.

Ullman, S.E., \& Brecklin, L.R. (2002). Sexual assault history and suicidal behavior in a national sample of women. Suicide and Life-Threatening Behavior, 32, 117-130.

Ullman, S.E., \& Filipas, H. (2001a). Predictors of PTSD symptom severity and social reactions in sexual assault victims. Journal of Traumatic Stress, 14, 369-389.

Ullman, S.E., \& Filipas, H.H. (2001b). Correlates of formal and informal support seeking in sexual assault victims. Journal of Interpersonal Violence, 16, 1028-1047.

Ullman, S.E., Filipas, H.H., Townsend, S.M., \& Starzynski, L. (2005). Trauma exposure, PTSD, and problem drinking among sexual assault survivors. Journal of Studies on Alcohol, 66, 610-619.

Ullman, S.E., Townsend, S.M., Filipas, H.H., \& Starzynski, L.L. (2007). Structural models of the relations of assault severity, social support, avoidance coping, self-blame, and PTSD among sexual assault survivors. Psychology of Women Quarterly, 31, 23-37.

Ullman, S.E., Filipas, H.H., Townsend, S.M., \& Starzynski, L.L. (2007). Psychosocial correlates of PTSD symptom severity in sexual assault survivors. Journal of Traumatic Stress, 20, 
821-831.

Valentiner, D.P., Riggs, D., Foa, E.B., \& Gershuny, B.S. (1996). Coping strategies and PTSD in female victims of sexual assault and nonsexual assault. Journal of Abnormal Psychology, $105,455-458$.

Weissman, M.M., Sholomskas, D., Pottenger, M., Prusoff, B.A., \& Locke, B.Z. (1977). Assessing depressive symptoms in five psychiatric populations: A validation study. American Journal of Epidemiology, 106, 203-214.

Zung, B. J. (1980). Factor structure of the Michigan Alcoholism Screening Test (MAST) in a psychiatric outpatient population. Journal of Clinical Psychology, 36, 1024-1030. 


\section{Footnote}

1. We also conducted bivariate analyses to examine relations between suicidal ideation and attempts and the following variables: educational level; marital status; age at time of assault; level of emotional upset at time of assault; whether the participant felt her life was threatened, actively resisted, was injured, or was using intoxicants at the time of the assault; whether the perpetrator was using intoxicants at time of assault, was a stranger, used force, or used a weapon; whether the participant disclosed her ASA to informal sources; social resources (number of confidantes); frequency of social contact; self-distraction, active coping, denial, emotional support, instrumental support, venting, positive reframing, planning, and religion subscales of the COPE; and the egocentric reactions subscale of the SRQ. Although some of the relations were significant, they did not meet the strict criteria we set to control for the number of analyses conducted $(p>.005)$. Results from these analyses and the full correlation matrix are available upon request.

2. Only the final block of each hierarchical logistic regression model is presented. Results from all five blocks are available upon request. 
Table 1

Final Hierarchical Logistic Regression Models Predicting Serious Suicidal Ideation and Attempts

\begin{tabular}{|c|c|c|c|c|c|c|c|}
\hline \multicolumn{4}{|c|}{$\begin{array}{l}\text { Serious Suicidal Ideation } \\
\qquad(N=544)\end{array}$} & \multicolumn{4}{|c|}{$\begin{array}{l}\text { Suicide Attempts } \\
\qquad(N=440)\end{array}$} \\
\hline Predictors & $\mathrm{B}$ & Wald & OR & Predictors & $\mathrm{B}$ & Wald & OR \\
\hline Age & $-.02 * *$ & 6.30 & .98 & Employed & -.28 & 1.37 & .75 \\
\hline Ethnicity & $-.44 *$ & 4.82 & .65 & Bisexual & .22 & .52 & 1.25 \\
\hline Bisexual & $.56^{\dagger}$ & 3.52 & 1.74 & Lesbian & .46 & .71 & 1.59 \\
\hline Lesbian & .66 & 1.76 & 1.93 & CSA history & $.57 *$ & 4.96 & 1.76 \\
\hline CSA history & $.34^{\dagger}$ & 2.86 & 1.41 & Traumatic life events & $.11^{\dagger}$ & 3.08 & 1.11 \\
\hline Traumatic life events & .08 & 2.45 & 1.09 & Completed rape & $.56^{\dagger}$ & 3.01 & 1.75 \\
\hline Multiple perpetrators & $.45^{\dagger}$ & 2.80 & 1.57 & Multiple perpetrators & .20 & .38 & 1.22 \\
\hline PTSD diagnosis & .13 & .34 & 1.14 & PTSD diagnosis & -.03 & .01 & .98 \\
\hline Significant depression & $.37^{\dagger}$ & 3.02 & 1.45 & Significant depression & .19 & .47 & 1.21 \\
\hline Illicit drug user & -.14 & .46 & .87 & Problem drinker & .00 & .00 & 1.00 \\
\hline Getting along with others & .15 & .98 & 1.16 & Illicit drug user & $.44^{\dagger}$ & 2.86 & 1.55 \\
\hline Satisfaction with social support & .04 & .09 & 1.04 & Disclosed to formal sources & $.53^{*}$ & 4.25 & 1.69 \\
\hline COPE Subscales & & & & Getting along with others & .11 & .37 & 1.11 \\
\hline Substance use & $.11^{*}$ & 4.76 & 1.12 & Satisfaction with social support & -.15 & 1.35 & .86 \\
\hline Behavioral disengagement & -.06 & .72 & .94 & Control over recovery & $-.32^{\dagger}$ & 2.94 & .73 \\
\hline Acceptance & .03 & .36 & 1.03 & COPE Subscales & & & \\
\hline Self-blaming & $.12 *$ & 4.42 & 1.13 & Substance Use & .06 & .82 & 1.06 \\
\hline SRQ Subscales & & .05 & .96 & Behavioral Disengagement & .00 & .00 & 1.00 \\
\hline Emotional support & -.04 & .23 & .90 & Humor & .10 & 1.79 & 1.11 \\
\hline Controlling reactions & -.10 & & & Self-blaming & .05 & .62 & 1.06 \\
\hline Treat differently & .12 & .38 & 1.13 & SRQ Subscales & & & \\
\hline \multirow[t]{4}{*}{ Aid/information support } & $-.26^{*}$ & 3.94 & .77 & Controlling reactions & -.17 & .38 & .84 \\
\hline & & & & Distraction reactions & .03 & .02 & 1.03 \\
\hline & & & & Treat differently & .19 & .68 & 1.21 \\
\hline & & & & Blaming reactions & -.03 & .03 & .97 \\
\hline
\end{tabular}

